\title{
Association between functional performance and executive cognitive functions in an elderly population including patients with low ankle-brachial index
}

\author{
This article was published in the following Dove Press journal: \\ Clinical Interventions in Aging \\ 6 May 2015 \\ Number of times this article has been viewed
}

\author{
Naomi Vidal Ferreira' \\ Paulo Jannuzzi Cunha ${ }^{2}$ \\ Danielle Irigoyen da Costa ${ }^{3}$ \\ Fernando dos Santos' \\ Fernando Oliveira Costa' \\ Fernanda Consolim- \\ Colombo ${ }^{4}$ \\ Maria Cláudia Irigoyen' \\ 'Heart Institute, Medical School, \\ Universidade de São Paulo, São Paulo, \\ SP, Brazil; ${ }^{2}$ Neuroimaging in Psychiatry \\ Laboratory, Department of Psychiatry, \\ Medical School, Universidade de \\ São Paulo, São Paulo, SP, Brazil; \\ ${ }^{3}$ Rio Grande do Sul Cardiology \\ Institute, Fundação Universitária de \\ Cardiologia, Porto Alegre, RS, Brazil; \\ ${ }^{4}$ Medical School, Universidade Nove \\ de Julho, São Paulo, SP, Brazil
}

Introduction: Peripheral arterial disease, as measured by the ankle-brachial index (ABI), is prevalent among the elderly, and is associated with functional performance, assessed by the 6-minute walk test (6MWT). Executive cognitive function (ECF) impairments are also prevalent in this population, but no existing study has investigated the association between ECF and functional performance in an elderly population including individuals with low ABI.

Aim: To investigate the association between functional performance, as measured by the 6MWT, and loss in ECF, in an elderly sample including individuals with low ABI.

Method: The ABI group was formed by 26 elderly individuals with low ABI (mean ABI: $0.63 \pm 0.19$ ), and the control group was formed by 40 elderly individuals with normal ABI (mean ABI: $1.08 \pm 0.07)$. We analyzed functional performance using the $6 \mathrm{MWT}$, global cognition using the Mini-Mental State Examination (MMSE), and ECF using the Digit Span for assessing attention span and working memory, the Stroop Color Word Test (SCWT) for assessing information processing speed and inhibitory control/impulsivity, and the Controlled Oral Word Association Test (COWAT) for assessing semantic verbal fluency and phonemic verbal fluency. We also used a factor analysis on all of the ECF tests (global ECF).

Results: Before adjustment, the ABI group performed worse on global cognition, attention span, working memory, inhibitory control/impulsivity, semantic verbal fluency, and phonemic verbal fluency. After adjustment, the ABI group performance remained worse for working memory and semantic verbal fluency. In a simple correlation analysis including all of the subjects, the 6MWT was associated with global cognition, attention span, working memory, information processing speed, inhibitory control/impulsivity, semantic verbal fluency, and global ECF. After adjustment, all the associations remained statistically significant.

Conclusion: This study found an independent association between functional performance and ECF in an elderly population including low ABI individuals, showing that, in elderly populations with functional impairment, ECF may also be impaired.

Keywords: cognition, vascular disease, 6-minute walk test

\section{Introduction}

Lower extremity peripheral arterial disease (PAD), a cardiovascular disease (CVD) resulting from atherosclerotic processes affecting the lower limbs, ${ }^{1}$ is prevalent among the elderly. ${ }^{2}$ Low ankle-brachial index (ABI), the most utilized criterion for detecting $\mathrm{PAD},{ }^{3}$ may lead to pain on exertion, skeletal muscle atrophy and weakness, ${ }^{4}$ resulting
Correspondence: Naomi Vidal Ferreir Av Dr Eneas de Carvalho Aguiar, 44, Cerqueira Cesar, São Paulo, SP, CEP 05403-000, Brazil Email naomivferreira@gmail.com 
in loss of functional performance. ${ }^{5}$ Studies have shown that a low ABI is related to decreased walking speed ${ }^{6}$ even among asymptomatic subjects. ${ }^{7}$ However, physical dysfunction seems to increase with the severity of symptoms resulting from a low $\mathrm{ABI}{ }^{8}$

The 6-minute walk test (6MWT) has been utilized in several studies of low ABI populations, in order to investigate different outcomes of PAD. ${ }^{9-12}$ In many of these studies, symptoms resulting from low ABI and its severity were shown to be associated with and completely or partially explain shorter distances on the $6 \mathrm{MWT},{ }^{9-11}$ pointing to an important relationship with functional loss.

Cognitive impairment is also prevalent among the elderly. ${ }^{13}$ Executive cognitive functions (ECF), which encompass the cognitive abilities of making decisions, judging, and suiting behaviors in order to solve problems, ${ }^{14}$ like any other cognitive function, may be impaired in the elderly. ${ }^{13}$ This impairment can lead to poor treatment adherence ${ }^{15}$ and loss of independence ${ }^{13}$ and ultimately increase the risk of developing dementia itself. ${ }^{16}$ The different manifestations of CVD, as well as the risk factors that lead to its development, have been shown to associate with cognitive losses especially the ones related to executive functioning ${ }^{17}$ - that may increase with the severity ${ }^{18}$ and with the number of CVD manifestations. ${ }^{19}$

Thus, early detection of executive dysfunction and functional impairments in patients with low ABI may be useful to prevent future problems and cognitive decline that affect quality of life. To our knowledge, no existing study has investigated the specific relationship between ECF and functional performance in an elderly sample including individuals with low ABI. Given the associations mentioned earlier, we hypothesized that, in such individuals, functional performance, as measured by the 6MWT, will be associated with loss in ECF.

\section{Method}

\section{Population}

The low ABI group (ABI group) for the study was recruited consecutively from the Vascular Clinic at Hospital das Clínicas, in São Paulo, Brazil, from April 2011 to August 2013. The normal ABI group (control group) was recruited from elderly communities near the Hospital and was similar to the ABI group in terms of age and sex. The inclusion criterion for the ABI group was an $\mathrm{ABI}$ value $<1.00$, thus including borderline and PAD subjects in the ABI group, while the inclusion criterion for control group was an ABI value $\geq 1.00 .^{20}$
The exclusion criteria for both groups were history of stroke, epilepsy, psychotic disorder, traumatic brain injury and developmental delay, all assessed in self-reports. The study project was evaluated and approved by the Ethical Committee of the Hospital das Clínicas. All subjects were fully informed about the purpose and procedures of the study, and gave written informed consent.

\section{Sociodemographic investigation}

All individuals were contacted by phone and invited to attend a scheduled appointment at the hospital. We performed an interview collecting sociodemographic information such as age, sex, education level, social level, and family income.

\section{Clinical and functional assessment}

The weight and height of each participant were measured using a regular scale, and the body mass index (BMI) was calculated as the ratio between weight and squared height. Systolic blood pressure, diastolic blood pressure and heart rate were measured in the supine position, after 5 minutes of rest, and repeated after 1 minute. The second measurement was considered in the analysis. With the subject still in the supine position, the ABI was measured using a calf, a sphygmomanometer, and a portable vascular Doppler (DV 610, Medmega, SP, Brazil); systolic pressures were measured in the following order: left brachial artery, left dorsalis pedis artery, left posterior tibial artery, right dorsalis pedis artery, right posterior tibial artery, and right brachial artery. The ABI value for each leg was calculated as the ratio between the highest pressure in the arms and the highest pressure in each leg. The lowest value between the two legs was considered in the analysis. ${ }^{21}$ The 6MWT was performed in a $20 \mathrm{~m}$ hall, and the subject was instructed to walk for 6 minutes, according to his or her tolerance, and to slow down or stop if necessary. The time was registered by the researcher, and every minute, words of encouragement were spoken. The test was interrupted every time the individual cited leg pain that did not allow him or her to continue the activity, but the timer continued to run during this period, and the participant resumed activity as soon as the pain attenuated. The total distance walked by the subject was considered in the analysis. $^{22}$

\section{Executive cognitive functions assessment}

The cognitive assessment consisted of three steps. In the first step we assessed the intelligence quotient (IQ) and psychiatric symptoms, for use in the correction of the analysis, given 
their association with cognitive performance. The Block Design and the Vocabulary subtests of the Wechsler Adult Intelligence Scale - third edition (WAIS-III) were utilized as a short form of IQ assessment. On the Block Design subtest, the subject is presented with geometric figures in two colors, increasing in complexity, and is asked to reproduce them with blocks in the same colors, in a certain amount of time. Each completed figure was scored, and the total score was computed. On the Vocabulary subtest, the subject is presented with spoken words, increasing in difficulty, and is asked to tell their meanings or their synonyms. Every correct word was scored, and the total score was computed. Scores for both subtests were added and weighted to be transformed into the IQ value by age groups. ${ }^{23}$ The Beck Depression Inventory is a self-administered test assessing depressive symptoms. It is composed of 21 questions, which go from 0 to 3, assessing psychological and physical symptoms. The total score was computed and was used in the analysis. The Beck Anxiety Inventory is also a self-administered test assessing anxiety symptoms. It is also composed of 21 questions, which go from 0 to 3 , assessing psychological and physical symptoms. The total score was computed and used in the analysis. ${ }^{24}$

In the second step, we assessed global cognition. The Mini-Mental State Examination (MMSE) is the most utilized screening of global cognition. It is composed of 19 questions or commands, divided into 6 cognitive domains: orientation, immediate recall, attention and calculation, delayed recall, language, and construction. We used the total score in the analysis (up to 30 points). ${ }^{25}$

In the third step, we assessed ECF. The Digit Span test assesses verbal attention and is composed of two tasks: Digit Forward, assessing attention span, and Digit Backward, assessing working memory. In the first task, sequences of numbers with an increasing degree of difficulty are presented to the subject, and he or she is asked to reproduce them in the same order. In the second task, different sequences of numbers with an increasing degree of difficulty are presented to the subject, and he or she is asked to reproduce them in reverse order. The score on each task goes up to 14 . We used separate scores for each task in the analysis. ${ }^{23}$

The Controlled Oral Word Association Test (COWAT) assesses verbal fluency, and it is a test in which the subject is asked to name specific kinds of words within 1 minute. The "Animals" category was used to assess semantic verbal fluency, and the "Letters" category, using the letters "F," "A", and "S" (FAS), was used to assess phonemic verbal fluency. We used the total score for the "Animals" category and the sum of the scores on the letters F, A and S for the "Letters" category. ${ }^{26}$
The Stroop Color Word Test (SCWT) is a test in which the subject is asked to inhibit the reading of the written word and indicate the color in which the word is written. The test is composed of three different parts, with colored figures/words, which increase in difficulty, and the time the subject takes to complete each part is registered. The first one assesses information processing speed and the second and third ones assess inhibitory control/impulsivity. We utilized separate times for each part. ${ }^{26}$

Executive functions, cognitive aspects that involve multiple domains, are all related to the functioning of the prefrontal cortex, and belong to the same cognitive construct. ${ }^{14}$ Thus, in addition to the separate scores for each test, we also analyzed a unit of every ECF category verified in the third step of the cognitive assessment.

\section{Covariates}

- Education level: This variable was used as a covariate because it is closely related to cognition and cognitive loss, ${ }^{27}$ in either young and elderly populations, ${ }^{28,29}$ and could bias the performance of the groups. Number of years of formal education was used to represent the education level.

- Social level (socioeconomic level): Social level has also been associated with cognitive performance, and was measured in this study to be used as another covariate. ${ }^{30}$ The level was defined by an instrument based on the number of material goods the person possesses at home. ${ }^{31}$

- Family income: Low income has been associated with poor performance on cognitive tests. Therefore, we used this variable as a covariate, since it could influence the analysis. ${ }^{32}$ Family income was based on total monthly household income.

- Intelligence quotient: Intellectual performance is also related to either poor or favorable results in cognitive assessment. ${ }^{33}$ That is why IQ was measured in this study, and used as another covariate in the analysis. The description of the assessment can be found in the study method.

- Depressive symptoms: There is evidence to indicate that depressive symptoms can also impair cognition, especially in the elderly. ${ }^{34}$ Thus, we utilized these symptoms as another covariate in the analysis. The description of this assessment also can be found in the study method.

- Anxiety symptoms: Elderly complaints about cognitive difficulties can also be associated to anxiety symptoms. ${ }^{35}$ Therefore, we utilized this variable as a covariate to avoid its bias in the analysis. The description of the assessment can be found in the study method. 


\section{Statistical analysis}

Comparative analyses on the groups' performance were done using the Chi-square test for the categorical variables and the Student's $t$-test and the Mann-Whitney test for the continuous parametric and nonparametric variables, respectively.

Pearson correlation analyses of the total study sample were used to investigate the associations between functional performance and global cognition/ECF. Partial correlation analyses were performed to investigate the associations between functional performance and global cognition/ECF, adjusted for the confounding variables described in the previous section.

Principal component analysis was used for two purposes: first, to generate a global factor for socioeconomic characteristics, uniting the information on education level, social level, family income, and IQ, because they were highly correlated (minimum correlation between them was $R=0.482, P<0.001$ ), in order to generate a new factor that could unite their characteristics. The new variable was saved, named "sociodemographic factor", and utilized in the adjustment analysis, instead of the separate variables, along with depressive symptoms and anxiety symptoms. A similar process was used as a second purpose, which was to generate a global factor for ECF, identifying the common variance in the Digit Forward, Digit Backward, SCWT I, SCWT II, SCWT III, COWAT - FAS, and COWAT Animals tests, due to their mentioned similarity in terms of cognitive constructs. The resulting factor values are decreasing and negatively related to our variables of interest. The new variable was saved, named "ECF factor", and utilized in the analysis, along with the independent scores for each ECF measurement.

\section{Results}

During the research period, 32 individuals with low ABI were contacted, 27 agreed to participate in the study, and 26 actually came to the examination and were included in the study sample. For the control group, 41 individuals (with similar ages and sex to the ABI group) were contacted, of whom 40 agreed to participate, and all of them came to the examination and were included in the study sample.

Sociodemographic, clinical, and functional characteristics are described in Table 1. The mean age for the control

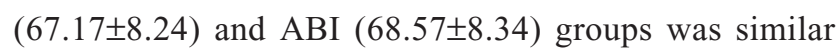
$(P=0.504)$, and so were male (control $=65.4 \%, \mathrm{n}=17$ vs

Table I Sociodemographic, clinical and functional characterization

\begin{tabular}{|c|c|c|c|}
\hline Variable & Control $(n=40)$ & $A B I(n=26)$ & $P$-value \\
\hline \multicolumn{4}{|l|}{ Age } \\
\hline Mean (years) & $67.17( \pm 8.24)$ & $68.57( \pm 8.34)$ & $0.504^{\mathrm{a}}$ \\
\hline Range & $54-88$ & $53-87$ & \\
\hline Sex & & & $0.812^{\mathrm{b}}$ \\
\hline Male & $65.4 \%(n=17)$ & $62.5 \%(n=25)$ & \\
\hline Female & $34.6 \%(n=9)$ & $37.5 \%(n=15)$ & \\
\hline Education level (years) & $12.85( \pm 5.16)$ & $8.30( \pm 4.76)$ & $0.00 I^{a}$ \\
\hline Social level & & & $0.029^{b}$ \\
\hline A & $5 \%(n=2)$ & $0 \%(n=0)$ & \\
\hline B & $62.5 \%(n=25)$ & $30.8 \%(n=8)$ & \\
\hline C & $17.5 \%(n=7)$ & $38.5 \%(n=10)$ & \\
\hline D & $0 \%(n=0)$ & $7.7 \%(n=2)$ & \\
\hline $\mathrm{E}$ & $0 \%(n=0)$ & $0 \%(n=0)$ & \\
\hline Family income (\$ per month) & $2491.29( \pm 1601.77)$ & $1227.35( \pm 755.62)$ & $0.002^{\mathrm{a}}$ \\
\hline IQ & III.94 ( $( \pm 8.96)$ & $98.47( \pm 25.06)$ & $0.007^{a}$ \\
\hline BDI & $6.79( \pm 5.23)$ & $12.56( \pm 9.30)$ & $0.008^{a}$ \\
\hline BAl & $5.47( \pm 4.59)$ & I I.48 ( \pm 7.23$)$ & $0.00 I^{a}$ \\
\hline BMI $\left(\mathrm{kg} / \mathrm{m}^{2}\right)$ & $25.49( \pm 3.84)$ & $25.81( \pm 4.65)$ & $0.773^{\mathrm{a}}$ \\
\hline $\mathrm{SBP}(\mathrm{mmHg})$ & $134.68( \pm 20.04)$ & $147.05( \pm 22.93)$ & $0.099^{a}$ \\
\hline $\mathrm{DBP}(\mathrm{mmHg})$ & $80.50( \pm 10.85)$ & $80.20( \pm 12.68)$ & $0.94 I^{a}$ \\
\hline HR (bpm) & $66.31( \pm 13.34)$ & $63.78( \pm 10.36)$ & $0.533^{\mathrm{a}}$ \\
\hline$A B I$ & $1.08( \pm 0.07)$ & $0.63( \pm 0.19)$ & $0.00 I^{a}$ \\
\hline 6MWT (m) & $394.74( \pm 88.28)$ & $294.20( \pm 76.05)$ & $0.00 \mathrm{I}^{\mathrm{a}}$ \\
\hline
\end{tabular}

Notes: a ${ }^{-G e n e r a l ~ L i n e a r ~ M o d e l ; ~}{ }^{b}$ chi-squared test. Significant $P$-values are highlighted in bold.

Abbreviations: IQ, intelligence quotient; BDI, Beck Depression Inventory; BAI, Beck Anxiety Inventory; BMI, body mass index; SBP, systolic blood pressure; DBP, diastolic blood pressure; $\mathrm{HR}$, heart rate; $\mathrm{ABI}$, ankle-brachial index; $6 \mathrm{MWT}$, 6-minute walk test. 
$\mathrm{ABI}=62.5 \%, \mathrm{n}=25 ; P=0.812)$ and female (control $=34.6 \%$, $\mathrm{n}=9$ vs $\mathrm{ABI}=37.5 \%, \mathrm{n}=15 ; P=0.812)$ sex frequencies. On the other hand, the ABI group had a lower education level (control $=12.85 \pm 5.16$ vs $\mathrm{ABI}=8.30 \pm 4.76 ; P=0.001$ ), lower distribution of social level $(P=0.029)$, lower family income (control $=2,491.29 \pm 1601.77$ vs $\mathrm{ABI}=1,227.35 \pm 755.62$, $P=0.002$ ), lower IQ levels (control $=111.94 \pm 8.96 \mathrm{vs}$ $\mathrm{ABI}=98.47 \pm 25.06, P=0.007$ ), a higher prevalence of depressive symptoms (control $=6.79 \pm 5.23$ vs $\mathrm{ABI}=12.56 \pm 9.30$, $P=0.008)$, and a higher prevalence of anxiety symptoms (control $=5.47 \pm 4.59$ vs $\mathrm{ABI}=11.48 \pm 7.23, P=0.001$ ).

The groups were similar in some of the clinical characteristics, such as BMI (control $=25.49 \pm 3.84 \mathrm{~kg} / \mathrm{m}^{2}$ vs $\left.A B I=25.81 \pm 4.65 \mathrm{~kg} / \mathrm{m}^{2} ; P=0.773\right)$, systolic blood pressure (control $=134.68 \pm 20.04 \mathrm{mmHg}$ vs $\mathrm{ABI}=147.05 \pm 22.93 \mathrm{mmHg} ; P=0.099)$, diastolic blood pressure (control $=80.50 \pm 10.85 \mathrm{mmHg}$ vs $\mathrm{ABI}=80.20 \pm 12.68 \mathrm{mmHg}$; $P=0.941)$, and heart rate $($ control $=66.31 \pm 13.34 \mathrm{bpm}$ vs $\mathrm{ABI}=63.78 \pm 10.36 \mathrm{bpm} ; P=0.533)$. However, the ABI group had lower values of $\mathrm{ABI}$ (control $=1.08 \pm 0.07$ vs $\mathrm{ABI}=0.63 \pm 0.19 ; P=0.001$ ), as expected, and walked shorter distances in the 6MWT (control $=394.74 \pm 88.28 \mathrm{~m}$ vs $\mathrm{ABI}=294.20 \pm 76.05 \mathrm{~m} ; P=0.001)$.

In the comparative analysis of ECF between groups (shown in Table 2), in the unadjusted model, the ABI group performed worse on global cognition (control $=28.55 \pm 1.46$ vs $\mathrm{ABI}=27.44 \pm 1.73 ; P=0.007$ ). It also performed worse on several ECF subdomains, such as attention span (control $=5.94 \pm 1.98$ vs $\mathrm{ABI}=4.80 \pm 1.19 ; P=0.023)$, working memory (control $=5.11 \pm 1.72$ vs $\mathrm{ABI}=3.90 \pm 1.20 ; P=0.008$ ), inhibitory control (control $=22.89 \pm 8.91$ vs $A B I=30.14 \pm 14.29$, $P=0.015)$, semantic verbal fluency (control $=18.92 \pm 7.49$ vs
$\mathrm{ABI}=15.53 \pm 3.55 ; P=0.036)$, and phonemic verbal fluency ( control $=35.27 \pm 15.04$ vs $\mathrm{ABI}=26.92 \pm 10.12 ; P=0.016$ ). After adjustment, working memory performance $(P=0.013)$ and phonemic verbal fluency $(P=0.005)$ remained worse for ABI patients.

\section{Association between functional performance and executive cognitive functions}

In the analysis of the association between functional performance and ECF (Figure 1), the unadjusted model showed that the $6 \mathrm{MWT}$ was associated with global cognition ( $\rho=0.412 ; P=0.001)$, attention span $(\rho=0.427 ; P=0.001)$, working memory $(\rho=0.360 ; P=0.008)$, information processing speed $(\rho=-0.306 ; P=0.016)$, inhibitory control/impulsivity $(\rho=-0.366 ; P=0.003)$, phonemic verbal fluency $(\rho=0.365$; $P=0.003)$, and global ECF $(\rho=-0.332 ; P=0.018)$. After adjustment (Table 3 ), the 6MWT remained associated with global cognition $(r=0.375, P=0.015)$, attention $\operatorname{span}(r=0.371$, $P=0.016)$, working memory $(r=0.373, P=0.015)$, information processing speed $(r=-0.332, P=0.032)$, inhibitory control/ impulsivity ( $r=-0.352, P=0.022)$, phonemic verbal fluency $(r=0.412, P=0.007)$, and global ECF $(r=-0.444, P=0.003)$.

\section{Discussion}

This study found an independent association between functional performance and ECF in an elderly population including low ABI individuals. The performance in the 6MWT was independently associated with global cognition, attention span, working memory, information processing speed, inhibitory control/impulsivity, phonemic verbal fluency, and global ECF.

Table 2 Comparison of ECF performance between groups

\begin{tabular}{|c|c|c|c|c|}
\hline Variable & Control $(n=40)$ & $A B I(n=26)$ & Unadjusted & Adjusted $^{a}$ \\
\hline MMSE & $28.55( \pm 1.46)$ & $27.44( \pm I .73)$ & 0.007 & 0.270 \\
\hline \multicolumn{5}{|l|}{ Digit Span } \\
\hline Digit Forward & $5.94( \pm 1.98)$ & $4.80( \pm 1.19)$ & 0.023 & 0.062 \\
\hline Digit Backward & $5.11( \pm 1.72)$ & $3.90( \pm 1.20)$ & 0.008 & 0.013 \\
\hline \multicolumn{5}{|l|}{ SCWT } \\
\hline I & I6.II ( $( \pm 6.35)$ & |8.8| ( $( \pm 6.98)$ & 0.116 & 0.165 \\
\hline II & $22.89( \pm 8.91)$ & $30.14( \pm 14.29)$ & 0.015 & 0.084 \\
\hline III & $40.70( \pm 19.21)$ & $43.00( \pm 18.18)$ & 0.635 & 0.949 \\
\hline \multicolumn{5}{|l|}{ COWAT } \\
\hline Letters FAS & I $8.92( \pm 7.49)$ & 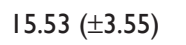 & 0.036 & 0.005 \\
\hline Animals & $35.27( \pm 15.04)$ & $26.92( \pm 10.12)$ & 0.016 & 0.228 \\
\hline ECF factor & $-0.08( \pm 1.07)$ & $0.37( \pm 0.82)$ & 0.172 & 0.056 \\
\hline
\end{tabular}

Notes: ${ }^{2}$ Adjusted for sociodemographic factor, depressive symptoms, and anxiety symptoms. Significant $P$-values were highlighted in bold.

Abbreviations: MMSE, Mini-Mental State Examination; SCWT, Stroop Color Word Test; COWAT, Controlled Oral Word Association Test; ECF, executive cognitive functions; $A B I$, ankle-brachial index. 
(A)

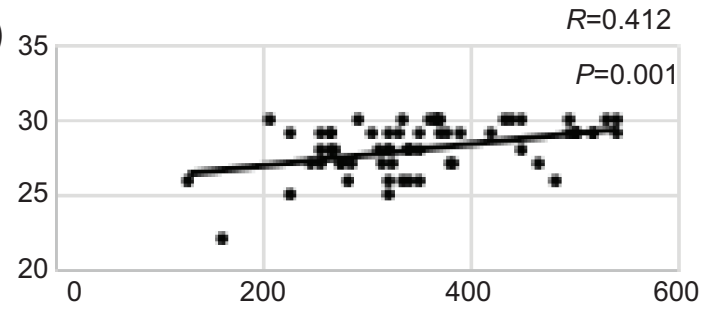

(C)

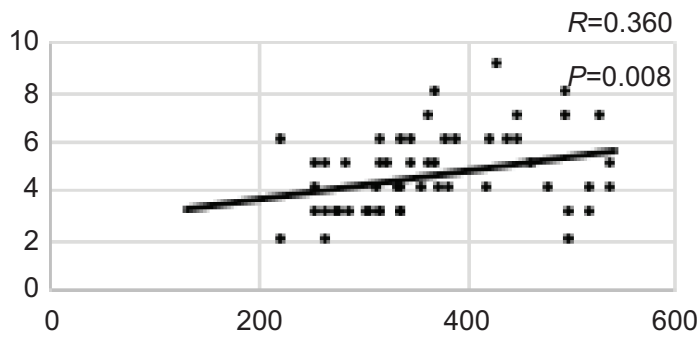

(E)

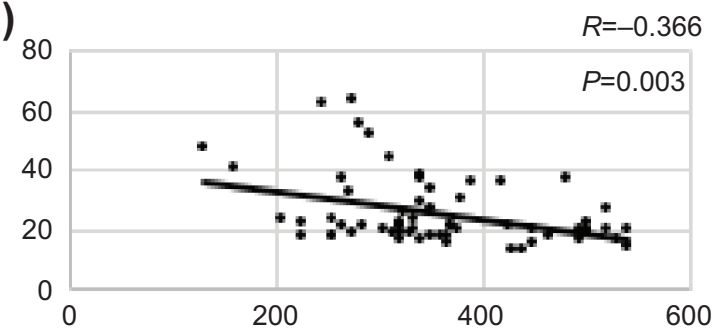

(G)

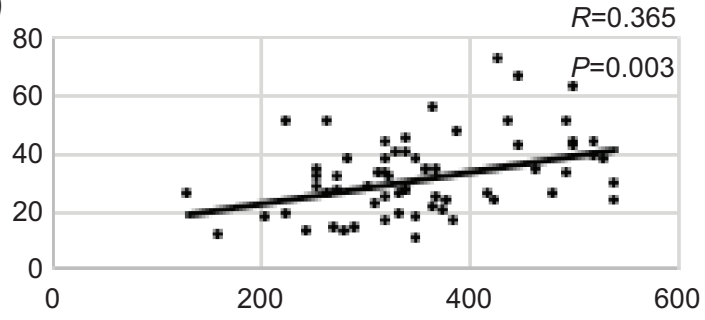

(B)

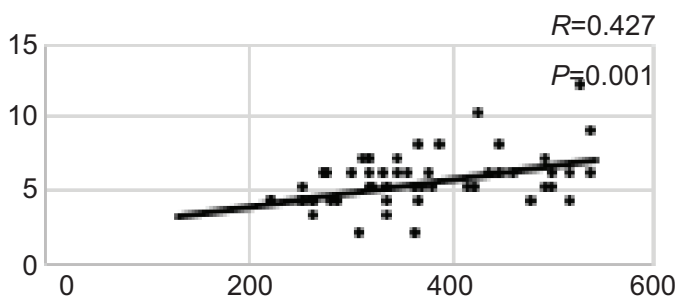

(D)

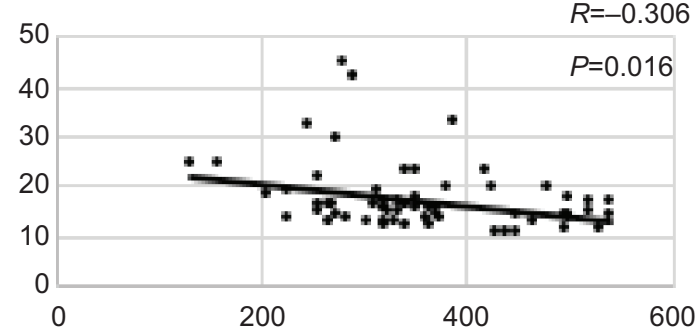

$(\mathrm{F})$

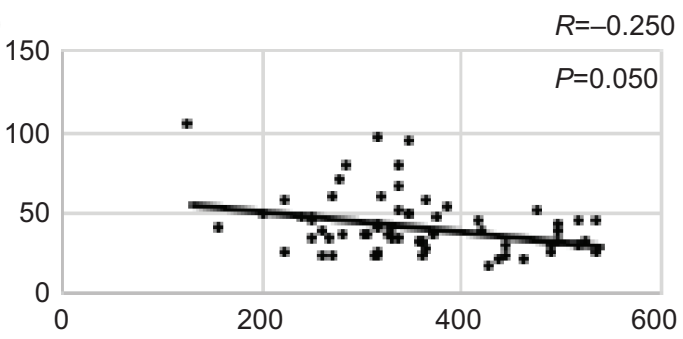

(H)

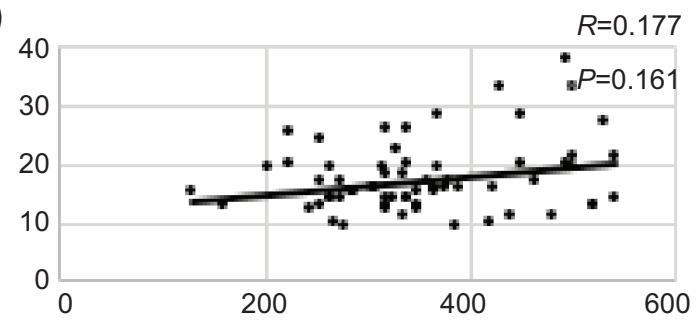

(l)

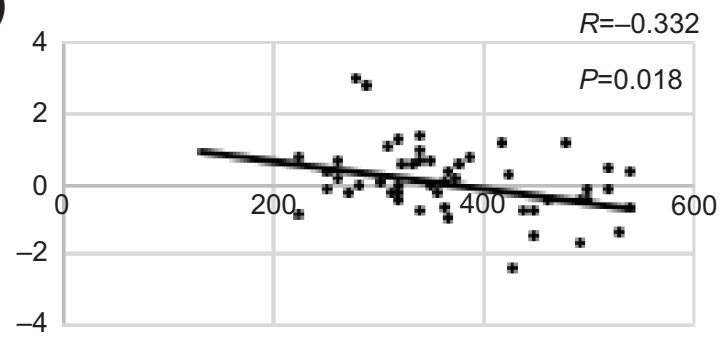

Figure I Associations between functional performance and ECF.

Notes: (A) 6MWT vs MMSE; (B) 6MWT vs Digit Forward; (C) 6MWT vs Digit Backward; (D) 6MWT vs SCWT I; (E) 6MWT vs SCWT II; (F) 6MWT vs SCWT III; (G) 6MWT vs COWAT - letters FAS; (H) 6MWT vs COWAT - Animals; (I) 6MWT vs ECF factor.

Abbreviations: 6MWT, 6-minute walk test; MMSE, Mini-Mental State Examination; SCWT, Stroop Color Word Test; COWAT, Controlled Oral Word Association Test; $E C F$, executive cognitive functions.

Our findings contribute to a growing body of evidence which shows that in elderly populations, impairment in functional performance might be associated with ECF impairment. In a prospective study of 2,776 elderly subjects, gait speed was associated with decline in attention and psychomotor speed after 5 years of follow-up. ${ }^{36}$ This association occurs in the opposite way as well. In a cross-sectional analysis of a normal ABI population of 3,075 subjects, the Digit Symbol Substitution Test was associated with performance on gait speed, chair stands, and standing balance tests. ${ }^{37} \mathrm{On}$ the other hand, low ABI has formerly been associated with ECF impairment even in its asymptomatic form. ${ }^{38}$ When it comes to cognition, ECF have also been associated with different manifestations of functional loss, such as decreases 
Table 3 Adjusted associations between functional performance and ECF

\begin{tabular}{lll}
\hline Variable & 6MWT $^{\mathbf{a}}$ & P-value \\
\hline MMSE & 0.375 & $\mathbf{0 . 0 1 5}$ \\
Digit Span & & \\
$\quad$ Digit Forward & 0.371 & $\mathbf{0 . 0 1 6}$ \\
$\quad$ Digit Backward & 0.373 & $\mathbf{0 . 0 1 5}$ \\
SCWT & & \\
I & -0.332 & $\mathbf{0 . 0 3 2}$ \\
II & -0.302 & 0.052 \\
III & -0.352 & $\mathbf{0 . 0 2 2}$ \\
COWAT & & \\
$\quad$ Letters FAS & 0.412 & $\mathbf{0 . 0 0 7}$ \\
Animals & 0.207 & 0.189 \\
ECF factor & -0.444 & $\mathbf{0 . 0 0 3}$
\end{tabular}

Notes: aAjusted for sociodemographic factor, depressive symptoms, and anxiety symptoms. Significant $P$-values were highlighted in bold.

Abbreviations: MMSE, Mini-Mental State Examination; SCWT, Stroop Color Word Test; COWAT, Controlled Oral Word Association Test; ECF, executive cognitive functions; 6MWT, 6-minute walk test.

in mobility, ${ }^{39}$ gait speed,${ }^{40}$ and route learning, ${ }^{41}$ as well as an increased risk of falls. ${ }^{42}$

To our knowledge, this is the first study to find an association between functional performance, as measured by the $6 \mathrm{MWT}$, and ECF in an elderly population including low ABI patients. One previous study, analyzing the relationship between functional performance and cognitive function in a low ABI population, utilized only the Clock Drawing Test, which does not assess ECF specifically. ${ }^{43}$ Some other studies have investigated the ECF of low ABI subjects, along with other cognitive functions, but have not assessed the functional performance of their populations. ${ }^{44-46}$

We also included a novel variable in the adjustment analysis. To our knowledge, the IQ has never been used as a covariate in any study assessing the association between functional performance and cognition in populations including individuals with low ABI. As mentioned, this variable is an important predictor of cognitive performance, ${ }^{33}$ and thus, should be considered carefully in this type of study.

The physiology of this specific association between functional performance and ECF might be explained, at least in part, by the pathophysiological mechanisms underlying atherosclerotic vascular disease, a process that might lead to hemorrhagic and ischemic major and minor tissue losses. ${ }^{47,48}$ As a systemic process, it might be related to peripheral and central impairments concomitantly, as was observed in this study. These findings highlight a dangerous association, especially in the elderly, and should be carefully considered, since any functional or cognitive impairment in the elderly may lead to loss of independence and quality of life.
The sample analyzed in our study showed that the group with lower ABI also had lower educational, social, and economic statuses. One possible reason for this difference might be related to the establishment of vascular impairment. People with lower educational levels and lower economic status might be less exposed to information on diseases, risk factors for their development and health care, which would lead to increased incidence of diseases, including vascular impairment.

\section{Acknowledgments}

This study was funded by Fundação de Amparo à Pesquisa do Estado de São Paulo (FAPESP; 10/51904-9, 2007/58942-0), Conselho Nacional de Pesquisa e Desenvolvimento (CNPq; 457581/2013-1, 306011/2010-7), Coordenação de Aperfeiçoamento de Pessoal de Nível Superior (CAPES; 074/2012) and PNPD Capes; DIC is a member of PNPD Capes. NVF and MCI received financial support from Coordenação de Aperfeiçoamento de Pessoal de Nível Superior (CAPES).

\section{Disclosure}

The authors report no conflicts of interest in this work.

\section{References}

1. Hirsch AT, Haskal ZJ, Hertzer NR, et al. ACC/AHA 2005 guidelines for the management of patients with peripheral arterial disease (lower extremity, renal, mesenteric, and abdominal aortic): executive summary. J Am Coll Cardiol. 2006;47(6):1239-1312.

2. Go AS, Mozaffarian D, Roger VL, et al. Heart disease and stroke statistics - 2013 update: a report from the American Heart Association. Circulation. 2013;127(1):E6-E245

3. Rooke TW, Hirsch AT, Misra S, et al. 2011 ACCF/AHA focused update of the guideline for the management of patients with peripheral artery disease (updating the 2005 guideline): a report of the American College of Cardiology Foundation/American Heart Association Task Force on Practice Guidelines. J Am Coll Cardiol. 2011;58(19): 2020-2045.

4. Parmenter BJ, Raymond J, Dinnen PJ, Lusby RJ, Singh MAF. Preliminary evidence that low ankle-brachial index is associated with reduced bilateral hip extensor strength and functional mobility in peripheral arterial disease. J Vasc Surg. 2013;57(4):963-973.

5. McDermott MM, Liu K, Greenland P, et al. Functional decline in peripheral arterial disease - associations with the ankle brachial index and leg symptoms. JAMA. 2004;292(4):453-461.

6. McDermott MM, Fried L, Simonsick E, Ling S, Guralnik JM. Asymptomatic peripheral arterial disease is independently associated with impaired lower extremity functioning - the women's health and aging study. Circulation. 2000;101(9):1007-1012.

7. Brass EP, Cooper LT, Hanson P, Hiatt WR. Association of clinical attributes and treadmill walking performance in patients with claudication due to peripheral artery disease. J Vasc Surg. 2013;58(2):396-403.

8. Gohil RA, Mockford KA, Mazari F, et al. Balance impairment, physical ability, and its link with disease severity in patients with intermittent claudication. Ann Vasc Surg. 2013;27(1):68-74.

9. Cahan MA, Montgomery P, Otis RB, Clancy R, Flinn W, Gardner A. The effect of cigarette smoking status on six-minute walk distance in patients with intermittent claudication. Angiology. 1999;50(7) $537-546$. 
10. McDermott MM, Greenland P, Guralnik JM, et al. Depressive symptoms and lower extremity functioning in men and women with peripheral arterial disease. J Gen Intern Med. 2003;18(6):461-467.

11. Rucker-Whitaker C, Greenland $P$, Liu K, et al. Peripheral arterial disease in african americans: clinical characteristics, leg symptoms, and lower extremity functioning. J Am Geriatr Soc. 2004;52(6):922-930.

12. Hillegass E. Walking speed in individuals with cardiovascular and pulmonary dysfunction. Top Geriatr Rehabil. 2012;28(2):110-112.

13. DeCarli C. Mild cognitive impairment: prevalence, prognosis, aetiology, and treatment. Lancet Neurol. 2003;2(1):15-21.

14. Godoy S, Dias NM, Trevisan BT, Menezes A, Seabra AG. Concepções teóricas acerca das funções executivas e das altas habilidades. Cadernos de pós-graduação em distúrbios do desenvolvimento. 2010;10(1):10.

15. Panos SE, Del Re AC, Thames AD, et al. The impact of neurobehavioral features on medication adherence in HIV: evidence from longitudinal models. AIDS Care. 2014;26(1):8.

16. Graham JE, Rockwood K, Beattie BL, et al. Prevalence and severity of cognitive impairment with and without dementia in an elderly population. Lancet. 1997;349(9068):1793-1796.

17. Phillips NA, Mate-Kole CC, Kirby RL. Neuropsychological function in peripheral vascular disease amputee patients. Arch Phys Med Rehabil. 1993;74(12):1309-1314.

18. Waldstein SR, Tankard CF, Maier KJ, et al. Peripheral arterial disease and cognitive function. Psychosom Med. 2003;65(5):757-763.

19. Phillips NA, Mate-Kole CC. Cognitive deficits in peripheral vascular disease. A comparison of mild stroke patients and normal control subjects. Stroke. 1997;28(4):777-784.

20. Rooke TW, Hirsch AT, Misra S, et al. Management of patients with peripheral artery disease (compilation of 2005 and 2011 ACCF/AHA Guideline Recommendations): a report of the American College of Cardiology Foundation/American Heart Association Task Force on Practice Guidelines. J Am Coll Cardiol. 2013;61(14):1555-1570.

21. Aboyans V, Criqui MH, Abraham P, et al. Measurement and interpretation of the ankle-brachial index: a scientific statement from the American Heart Association. Circulation. 2012;126(24):2890-2909.

22. McDermott MM, Greenland P, Liu K, et al. The ankle brachial index is associated with leg function and physical activity: the Walking and Leg Circulation Study. Ann Intern Med. 2002;136(12):873-883.

23. Weschler D. WAIS-III: Escala de Inteligência Weschler para Adultos: Manual/David Weschler; Adaptação e padronização de uma amostra brasileira Elizabeth do Nascimento. São Paulo, Brasil: Casa do Psicólogo; 2004. 271 p.

24. Cunha JA. Manual da versão em português das Escalas Beck. São Paulo: Casa do Psicólogo; 2001.

25. Folstein MF, Folstein SE, McHugh PR. "Mini-mental state". A practical method for grading the cognitive state of patients for the clinician. J Psychiatr Res. 1975;12(3):189-198.

26. Spreen O, Strauss E. A Compendium of Neuropsychological Tests. New York, NY: Oxford University Press; 1998.

27. Launer LJ, Dinkgreve MA, Jonker C, Hooijer C, Lindeboom J. Are age and education independent correlates of the Mini-Mental State Exam performance of community-dwelling elderly? J Gerontol. 1993; 48(6):271-277.

28. Farmer ME, Kittner SJ, Rae DS, Bartko JJ, Regier DA. Education and change in cognitive function. The Epidemiologic Catchment Area Study. Ann Epidemiol. 1995;5(1):1-7.

29. Osterweil D, Mulford P, Syndulko K, Martin M. Cognitive function in old and very old residents of a residential facility: relationship to age, education, and dementia. J Am Geriatr Soc. 1994;42(7):766-773.

30. Moraes C, Pinto JA, Lopes MA, Litvoc J, Bottino CM. Impact of sociodemographic and health variables on mini-mental state examination in a community-based sample of older people. Eur Arch Psychiatry Clin Neurosci. 2010;260(7):535-542.
31. (ABIPEME) ABDIdPdM. Critério ABA - ABIPEME. São Paulo: ABIPEME; 1991.

32. Berkman LF, Seeman TE, Albert M, et al. High, usual and impaired functioning in community-dwelling older men and women: findings from the MacArthur Foundation Research Network on Successful Aging. J Clin Epidemiol. 1993;46(10):1129-1140.

33. Dias NM, Trevisan BT, Menezes A, Godoy S, Seabra A. Dificuldades de aprendizagem e funções executivas. In: Capovil FC, Montiel JM, editors. Transtornos de aprendizagem. Porto Alegre: Artmed; 2011.

34. King D, Cox C, Lyness J, Caine E. Neuropsychological effects of depression and age in an elderly sample: a confirmatory study. Neuropsychology. 1995;9:10.399-408.

35. Paulo D, Yassuda M. Queixas de memória de idosos e sua relação com escolaridade, desempenho cognitivo e sintomas de depressão e ansiedade. Revista de Psiquiatria Clínica. 2010;37(1):23-26.

36. Inzitari M, Newman AB, Yaffe $K$, et al. Gait speed predicts decline in attention and psychomotor speed in older adults: the health aging and body composition study. Neuroepidemiology. 2007; 29(3-4):156-162.

37. Rosano C, Simonsick EM, Harris TB, et al. Association between physical and cognitive function in healthy elderly: the health, aging and body composition study. Neuroepidemiology. 2005;24(1-2):8-14.

38. Mangiafico RA, Sarnataro F, Mangiafico M, Fiore CE. Impaired cognitive performance in asymptomatic peripheral arterial disease: relation to C-reactive protein and D-dimer levels. Age Ageing. 2006;35(1):60-65.

39. Berryman N, Bherer L, Nadeau S, et al. Executive functions, physical fitness and mobility in well-functioning older adults. Exp Gerontol. 2013;48(12):1402-1409.

40. Killane I, Donoghue OA, Savva GM, Cronin H, Kenny RA, Reilly RB. Variance between walking speed and neuropsychological test scores during three gait tasks across the irish longitudinal study on aging (TILDA) dataset. Conf Proc IEEE Eng Med Biol Soc. 2013;2013:6921-6924.

41. Benke T, Karner E, Petermichl S, Prantner V, Kemmler G. Neuropsychological deficits associated with route learning in Alzheimer disease, MCI, and normal aging. Alzheimer Dis Assoc Disord. 2014;28(2):162-167.

42. Muir SW, Beauchet O, Montero-Odasso M, Annweiler C, Fantino B, Speechley M. Association of executive function impairment, history of falls and physical performance in older adults: a cross-sectional population-based study in eastern france. $J$ Nutr Health Aging. 2013;17(8):661-665.

43. Zimmermann LJ, Ferrucci L, Kiang Liu, et al. Poorer clock draw test scores are associated with greater functional impairment in peripheral artery disease: the Walking and Leg Circulation Study II. Vasc Med. 2011;16(3):173-181.

44. Singh-Manoux A, Britton AR, Marmot M. Vascular disease and cognitive function: evidence from the Whitehall II Study. J Am Geriatr Soc. 2003;51(10):1445-1450.

45. Rao R, Jackson S, Howard R. Neuropsychological impairment in stroke, carotid stenosis, and peripheral vascular disease: a comparison with healthy community residents. Stroke. 1999;30(10):2167-2173.

46. Vupputuri S, Shoham DA, Hogan SL, Kshirsagar AV. Microalbuminuria, peripheral artery disease, and cognitive function. Kidney Int. 2008;73(3):341-346.

47. Knepper JP, Henke PK. Diagnosis, prevention, and treatment of claudication. Surg Clin North Am. 2013;93(4):779-788.

48. Shimoyama T, Iguchi Y, Kimura K, et al. Stroke patients with cerebral microbleeds on MRI scans have arteriolosclerosis as well as systemic atherosclerosis. Hypertens Res. 2012;35(10):975-979. 
Clinical Interventions in Aging

\section{Publish your work in this journal}

Clinical Interventions in Aging is an international, peer-reviewed journal focusing on evidence-based reports on the value or lack thereof of treatments intended to prevent or delay the onset of maladaptive correlates of aging in human beings. This journal is indexed on PubMed Central, MedLine,

CAS, Scopus and the Elsevier Bibliographic databases. The manuscript management system is completely online and includes a very quick and fair peer-review system, which is all easy to use. Visit http://www.dovepress. $\mathrm{com} /$ testimonials.php to read real quotes from published authors.

Submit your manuscript here: http://www.dovepress.com/clinical-interventions-in-aging-journal 